Bioconversion of steviol glycosides into steviol by Microbacterium barkeri* $^{*}$

Hui-Ling Jianga, Yan Xuan ${ }^{\mathrm{a}}$, Qian Zenga, Qi-Ming Jimmy Yu ${ }^{\mathrm{b}}$, Yu-Qian

Zhang $^{\mathrm{c}}$, Yu-Ru Chen ${ }^{\mathrm{a}}$, Hai-Bo Luo ${ }^{\mathrm{a}}$, He Huang ${ }^{\mathrm{a}}$ and Qing Xu ${ }^{\mathrm{a}}$

${ }^{a}$ School of Food Science and Pharmaceutical Engineering, Nanjing Normal

University, Nanjing 210023, China; ${ }^{b}$ Environmental Engineering, Griffith School of Engineering, Griffith University, Brisbane, Queensland 4111, Australia; 'Taizhou College, Nanjing Normal University, Taizhou 225300, China

*CONTACT: Yu-Ru Chen, chenyuru@njnu.edu.cn; Hai-Bo Luo, luohaibo_1216@126.com. School of Food Science and Pharmaceutical Engineering, Nanjing Normal University, Nanjing 210023, China 


\section{Bioconversion of steviol glycosides into steviol by Microbacterium}

\section{barkeri}

\section{ABSTRACT}

The strain which degraded steviol glycosides to steviol (STE) was screened and isolated from soil samples. A phylogenetic tree was constructed and used to determine the taxonomic status of the strain. 16S rDNA sequence was ultimately used to identify the strain as Microbacterium barkeri XJ. The transformation product was detected and identified as STE by HPLC/LC-MS/IR analysis. The bioconversion rate of $1 \%$ (v/v) steviol glycosides (stevioside, rebaudioside A, rebaudioside C) into STE in basic medium were $100 \%$ within $24 \mathrm{~h}, 84 \mathrm{~h}$ and $144 \mathrm{~h}$, respectively. The results indicated $\mathrm{XJ}$ was more effective than mixed flora in the bioconversion of steviol glycosides to STE.

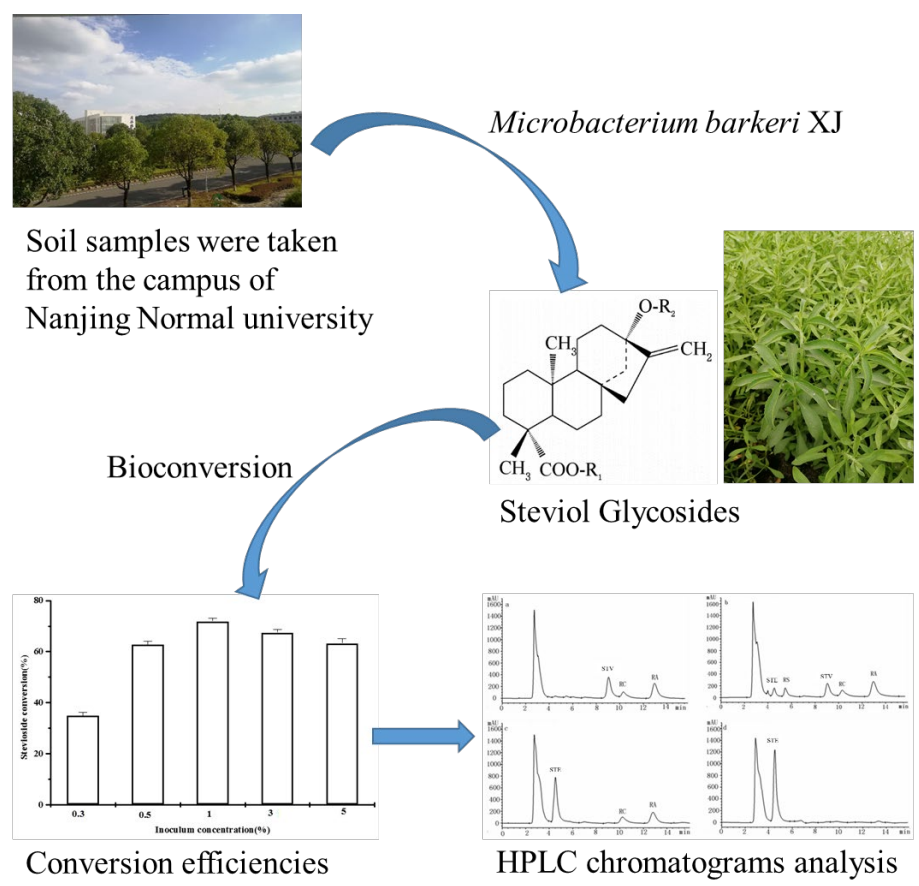

\section{KEYWORDS}

natural sweetener; stevioside; steviol; biotransform; Microbacterium barkeri 


\section{Introduction}

Stevia rebaudiana Bertoni (Bertoni) is a genus of about 150 species of herbs and shrubs in the Asteraceae (Compositae) family, and native to subtropical and tropical in South and Central America [1], widely introduced to China since 1990s, owing to its high sweetness.

Steviol glycosides, no-calorie sweetener, are glycoside derivatives of steviol (STE) [2]. They are 150-300 times sweeter than sucrose and are the main components of sweeteners extracted from the leaves of Stevia rebaudiana Bertoni [3]. They are mainly composed of stevioside (STV) and rebaudioside A (RA), accounting for $3-10 \%(\mathrm{w} / \mathrm{w})$ and $1 \%(\mathrm{w} / \mathrm{w})$, together with other components such as rebaudioside $\mathrm{C}$ (RC), dulcoside A and the extremely minor components rebaudiosides B, D, E and steviolbioside (Table 1 and Figure 1). STE, the aglycone of STV, has broad application prospects in the field of medicine for good bioactivity. Structural modification, such as the adding of $\alpha$-methylene cyclopentanone structure, can greatly increase the anti-tumor activity of STE [4].

The possible mutagenic and genotoxic effects of stevia extracts have been studied on bacterial cells and different mammalian species, and results demonstrated that stevia extracts are safe for use [5]. However, some aspects of the effects of stevia extracts on human health need further investigation $[6,7]$. STE had a weak mutagenic activity in the forward mutation assays [8]. In contrast, STE decreased glucose production and inhibited oxygen uptake [9]. Interacting with some drug transporters, STE was also considered as a drug modulator. Furthermore, its effects were found to 
be similar to those of gibberellin. It could regulate the growth of the plant, and stimulate seed germination and sprouting [10]. The metabolism and elimination of steviol glycosides in bacterial intestinal flora of rats [11], mice [12], pigs [2] and humans $[13,14]$ have been studied. In these processes steviol glycosides were converted into aglycone STE under the action of mixed flora in vivo. Researchers considered that the bioconversion of steviol glycosides by some bacterium species is the initial steps of the metabolism and elimination processes. It is therefore important to characterize the bioconversion processes of steviol glycosides by the bacterium strains involved in the metabolism and elimination processes. Based on previous studies, the biodegradation of STV and its related compounds by a newly identified Microbacterium barkeri was studied.

\section{Results}

\subsection{Screening and identification of the strain XJ}

It is generally recognized that two bacteria can be identified as the same strain when their sequence similarity is over 97\%. As shown in Figure 2, the full length of 16S rDNA sequence of strain XJ was 1439 bp. Blast analysis in GeneBank showed that the strain XJ was the most similar of $99.86 \%$ to M. barkeri. Phylogenetic tree also showed that the strain XJ has clustered with M. barkeri DSM20145 (Figure 3). Therefore, the strain XJ is most likely to be M. Barkeri (X77446).

\subsection{Analysis and identification of products}

Samples of steviol glycosides (STV, RA and RC) before, during and after bioconversion were analysed with the HPLC method and typical HPLC 
chromatograms were obtained (Figure 4). LC-MS analysis of the product ion scan spectrum was used to confirm the identity of the first hydrolysis product as shown in Figure 4a. In Figure 4b, two new peaks could be identified. The characteristic fragment ion of [M-H] ${ }^{-}$was identical to the STE standard that were all at $m / z$ 317.3. The spectral data of IR ( $\mathrm{KBr}$ flaking, $\mathrm{cm}^{-1}$ ) for it were 1690, 2950, 3280, 3460. 3460 $(-\mathrm{OH}), 1690(-\mathrm{COOH})$, identical to that of the STE standard (Figure 4c). Therefore, the new compound was identified as STE. There was another peak at $m / z 665.2$ (Figure $4 \mathrm{~b}$ ) which was an intermediate product of the biotransformation process and it was identified to be rubusoside (RS) as reported by Jiang et al [15].

\subsection{Effects of inoculum concentration on conversion rate}

The effects of inoculum concentration on STV conversion efficiency were studied using four different groups of PDA liquid medium containing $0.3 \%, 0.5 \%, 1 \%$, $3 \%$ and $5 \%(\mathrm{v} / \mathrm{v})$ of inoculum, respectively, to which $1 \%(\mathrm{v} / \mathrm{v})$ of steviol glycosides $(50 \mathrm{ml})$ was applied (Figure 5). As revealed in Figure 5, the highest conversion $(71.9 \%)$ of STV was obtained after $12 \mathrm{~h}$ of treatment with $1 \%(\mathrm{v} / \mathrm{v})$ inoculum concentration. This may be the sufficient oxygen and high activities of enzymes were presented at this concentration, which was favourable for STV conversion.

\subsection{Biological transformation}

The biological transformation of steviol glycosides were studied by determining the change of bioconversion efficiencies along with the treatment time prolongs (Figure 6). Figure 7 showed the chromatograms of the treatment medium at various times. The initial concentration of STV was $3.2 \mathrm{mg} / \mathrm{ml}$, and the concentration of STV 
decreased, while the conversion efficiency increased with the treatment time prolonging (Figure 7a). As mentioned earlier, there was an intermediate product of RS (Figure $7 b$ ) which indicated that the hydrolysis was achieved in a two-step process. The STV was completely eliminated and the conversion reached $100 \%$ after $24 \mathrm{~h}$ treatment. Similarly, an apparent decrease in RA concentration (from $3.2 \mathrm{mg} / \mathrm{ml}$ ) was also observed and the conversion after $24 \mathrm{~h}$ treatment was $72 \%$, and complete elimination was reached after $84 \mathrm{~h}$ (Figure 7c and 7d). In addition, the concentration of RC was almost unchanged and $98 \%$ of it still remained after $24 \mathrm{~h}$ treatment. 6 Days treatment period was needed to completely eliminate RC (Figure 7d). The relative elimination rates of substrates were in the order of STV $>$ RA $>$ RC (Figure 8).

\subsection{Separation and purification of STE}

The product STE was extracted by n-butanol, the organic phase was concentrated in vacuum, and the impurities such as esters were removed by petroleum ether/acetone $=(85: 15, \mathrm{v} / \mathrm{v})$. Finally, the solvent was volatilized in water bath. The purity of STE was about $90 \%$, and the yield was $81.6 \%$.

\section{Discussion}

M. barkeri was a newly identified and highly efficient strain that can be used for the bioconversion of steviol glycosides to STE in vitro. In previous studies, it was shown that STV $(2.5 \mathrm{mg} / \mathrm{ml})$ and RA $(3 \mathrm{mg} / \mathrm{ml})$ can be completely degraded to STE by a rat whole cell suspension within $48 \mathrm{~h}$ and $144 \mathrm{~h}$ [16]. In this study, STV (3.2 $\mathrm{mg} / \mathrm{ml}$ and RA $(3.2 \mathrm{mg} / \mathrm{ml})$ were completely eliminated after $24 \mathrm{~h}$ and $84 \mathrm{~h}$ of treatment, respectively. In addition, RC was eliminated after 6 days. In comparison, 
the conversion rates were relatively high and the substrate concentrations were also relatively higher.

By using the methods of HPLC/LC-MS/IR, the identity of the intermediate and final hydrolysis products were determined. STV was shown to be hydrolysed to the intermediate product RS and then to STE. RA was also completely hydrolysed to STE by $M$. barkeri, but a longer time was required ( $84 \mathrm{~h})$. During the period of 0-24 h, RA was first hydrolyzed to RS, and this intermediate product was rapidly converted into STE.

In summary, a strain with highly efficient and specific ability to bioconversion steviol glycosides was screened and identified from soil. It effectively bioconverted steviol glycosides (STV, RA and RC) into the final product STE at $24 \mathrm{~h}, 84 \mathrm{~h}$ and 144 h, respectively. The highest conversion rate to $1 \%$ STV was achieved when the inoculum of $M$. barkeri was $1 \%(\mathrm{~V} / \mathrm{V})$, which was advantageous in terms of time and energy consumption.

\section{Experimental}

\subsection{Chemicals and medium}

The potato dextrose agar (PDA) liquid medium contained 1\% steviol glycosides (STV, RA, and RC). Steviol glycoside samples were purchased from Pusaike Biotechnology Co. Ltd, Jiangxi Province, China. Standard samples of STE (purity > 99\%) were obtained from Zhangshu Chemical Technology Co. Ltd, Shanghai, China.

\subsection{Analytical methods}

Quantitative analysis of steviol glycosides was carried out by using high 
performance liquid chromatography (HPLC) method on an Agilent 1100 HPLC system. STV, RA, RC and their metabolites were separated on a Kromasil- $\mathrm{NH}_{2}$ column $(250 \mathrm{~mm} \times 4.6 \mathrm{~mm}$ I.D., $5 \mu \mathrm{m})$ at a column temperature of $25{ }^{\circ} \mathrm{C}$. The composition of the mobile phase was acetonitrile $/ \mathrm{H}_{2} \mathrm{O}(80: 20, \mathrm{v} / \mathrm{v})$ at a rate of 1.0 $\mathrm{ml} / \mathrm{min}$. UV detection was at $210 \mathrm{~nm}$. Liquid chromatography-mass spectrometry (LC-MS) was conducted on an Agilent 6460 HPLC system, coupled with negative electrospray ionization (ESI) tandem mass spectrometry (MS/MS) method. Mass spectra in the negative ion mode were operated under the following conditions: fragmenter voltage $=5 \mathrm{eV}$, voltage $=3500 \mathrm{~V}$, nebulizer pressure $=45$ psi, capillary temperature $=300^{\circ} \mathrm{C}, \mathrm{m} / \mathrm{z}$ range $=50-1000$. The analytical column used was a Kromasil- $\mathrm{NH}_{2}$ column $(250 \mathrm{~mm} \times 4.6 \mathrm{~mm}$ I.D., $5 \mu \mathrm{m})$, and the flow rate was 0.5 $\mathrm{ml} / \mathrm{min}$. The injection volume was $20 \mu \mathrm{l}$. Infrared spectroscopy (IR) was conducted on Nexus 670. MID-IR, scanning range $4000-400 \mathrm{~cm}^{-1}$.

\subsection{Isolation and identification of the strain}

Soil samples were collected from the campus of Nanjing Normal University, Jiangsu, China.

Genomic DNA of isolated strain was extracted using a SK1201-UNIQ-10 column type bacterial DNA Isolation Kit (Sangon, Shanghai, China). The 16S rDNA was amplified by polymerase chain reaction (PCR) using universal primers (27f, 5'-AGAGTTTGATCCTGGCTCAG-3' 1492r, 5'-GGTTACCTTGTTACGACTT-3'). The PCR system consisted of: 10 pmol of template; $1 \mu \mathrm{l}$ of primer up $(10 \mu \mathrm{M}) ; 1 \mu \mathrm{l}$ of primer down $(10 \mu \mathrm{M}) ; 1 \mu 1$ of dNTP mix 
(10 mM each); $5 \mu 110 *$ Taq reaction buffer; $0.25 \mu 1$ Taq DNA polymerase $(5 \mathrm{U} / \mu 1)$ and adding water to $50 \mu \mathrm{l}$. Amplification parameters were as follows: $5 \mathrm{~min}$ at $98{ }^{\circ} \mathrm{C}$; $35 \mathrm{~s}$ at $95{ }^{\circ} \mathrm{C}, 35 \mathrm{~s}$ at $55^{\circ} \mathrm{C}$, and $1 \mathrm{~min}$ at $72{ }^{\circ} \mathrm{C}$ for 35 cycles; with a final extension step of 8 min at $72{ }^{\circ} \mathrm{C}$. The $16 \mathrm{~S}$ rDNA gene was amplified and submitted to National Center for Biotechnology Information (NCBI) GeneBank for comparison with blast sequence database. The highly similar 16S rDNA sequences were obtained from the database, and analyzed by MegAlign software to construct phylogenetic trees.

\subsection{Bioconversion of steviol glycosides}

Microbaterium barkeri were added to the PDA liquid medium contained 1\% (v/v) of solutions of steviol glycosides $(50 \mathrm{ml})$. The medium was treated at $37{ }^{\circ} \mathrm{C}$ and 220 rpm for 6 days under aerobic conditions.

\section{Disclosure statement}

No potential conflict of interest was reported by the author(s)

\section{Funding}

This work was financially supported by the National Key Research and Development Program of China (2019YFA0904900), the Program for Jiangsu Excellent Scientific and Technological Innovation Team(17CXTD00014) and the Special Projects of Introduction of Foreign Technical and Managerial Talents (BX2019014). 


\section{References}

[1] C. Rosaria, M. Francesco, P. Mario, and P. Mario, Biofuel. Bioprod. Biorefin. 13, $445-452(2019)$

[2] D.D. Soejarto, E.M. Addo, and A.D. Kinghorn, J. Ethnopharmacol. 243, 112056 (2019).

[3] O. Kim, C. Simon, S. Angelika, S. Ernesto, D.M. Michael, Birger, and L.M. Birger, Microb. Cell. Fact. 15, 207-222 (2016).

[4] D.Y. Zhang, Y. Tang, K. Wang, X.M. Wu, and W.Y. Hua, J. Chin. Pharm. Univ. 41, 20-25 (2010).

[5] S. Casas-Grajales, K. Reres-Gordillojales, C.M. Cerda-García-Rojas, V. Tsutsumi, M.R. Lakshman, and P. Muriel, J. Appl. Toxicol. 39, 1118-1131 (2019).

[6] J. Jiang, L. Qi, Q. Wei, and F. Shi, Reprod. Toxicol. 76, 35-45 (2018).

[7] C. Schiano, V. Grimaldi, M. Franzese, C. Fiorito, F.D. Nigris, F. Donatelli, A. Soricelli, M. Salvatore, and C. Napoli, Toxicol. Vitro. 62, 104694 (2020).

[8] T. Terai, H. Ren, G. Mori, Y. Yamaguchi, and T. Hayashi, Chem. Pharm. Bull. 50, 1006-1010 (2002)

[9] M. Ritu and J. Nandini, J. Sci. Food. Agric. 96, 4231-4234 (2016).

[10] B.H. De Oliveira, J.C. Stiirmer, J.D. de Souza Filho, and R.A. Ayub, Phytochemistry. 69, 1528-1533 (2008).

[11] R.E. Wingard, J.P. Brown, F.E. Enderlin, J.A. Dale, R.L. Hale, and C.T. Seitz, Experientia. 36, 519-520 (1980).

[12] A.M. Hutapea, C. Toskulkao, D. Buddhasukh, P. Wilairat, and T. Glinsukon, J. 
Clin. Biochem. Nutr. 23, 166-186 (1996).

[13] E. Koyama, K. Kitazawa, Y. Ohori, O. Izawa, K. Kakegawa, A. Fujino, and M. Ui, Food. Chem. Toxicol. 41, 359-364 (2003a).

[14] E. Koyama, N. Sakai, Y. Ohori, K. Kitazawa, O. Izawa, K. Kakegawa, A. Fujino, and M. Ui, Food. Chem. Toxicol. 41, 875-883 (2003b).

[15] Z.Y. Jiang, Y.R. Chen, and H. Liu, Acta Microbiol. Sin. 51, 43-49 (2011).

[16] G.I. Kovylyaeva, G.A. Bakaleinik, I.Yu. Strobykina, V.I. Gubskaya, R.R. Sharipova, V.A. Al'fonsov, and A.G. Tolstikov, Chem. Nat. Compd. 43, 81-85 (2007). 
Table 1. Structures of steviol glycosides.

\begin{tabular}{|c|c|c|c|c|}
\hline No. & Compounds & Abbreviation & R1 & $\mathbf{R 2}$ \\
\hline 1 & Stevioside & STV & glc- & glc ${ }^{2}$ glc- \\
\hline 2 & Steviol & STE & $\mathrm{H}-$ & $\mathrm{H}-$ \\
\hline 3 & Stevia monoglycoside & SM & $\mathrm{H}-$ & glc- \\
\hline 4 & Steviolbioside & SB & H- & $\mathrm{glc}^{2}$-glc- \\
\hline 5 & Rubusoside & $\mathrm{RS}$ & glc- & glc- \\
\hline 6 & Rebaudioside A & RA & glc- & $\mathrm{glc}^{2}-\left[\mathrm{glc}^{3}\right]-\mathrm{glc}-$ \\
\hline 7 & Rebaudioside B & $\mathrm{RB}$ & $\mathrm{H}-$ & $\mathrm{glc}^{2}-\left[\mathrm{glc}^{3}\right]-\mathrm{glc}-$ \\
\hline 8 & Rebaudioside C & $\mathrm{RC}$ & glc- & $\mathrm{rha}^{2}-\left[\mathrm{glc}^{3}\right]$-glc- \\
\hline 9 & Rebaudioside D & $\mathrm{RD}$ & $\mathrm{glc}^{2}$-glc- & $\mathrm{glc}^{2}-\left[\mathrm{glc}^{3}\right]-\mathrm{glc}-$ \\
\hline 10 & Rebaudioside E & $\mathrm{RE}$ & $\mathrm{glc}^{2}$-glc- & glc $^{2}$-glc- \\
\hline 11 & Rebaudioside F & RF & glc- & xly ${ }^{2}-\left[\mathrm{glc}^{3}\right]-$ glc- \\
\hline 12 & Rebaudioside G & RG & glc- & $\mathrm{glc}^{3}$-glc- \\
\hline 13 & Rebaudioside $\mathrm{H}$ & RH & glc- & $\mathrm{glc}^{3}-\mathrm{rha}^{2}-\left[\mathrm{glc}^{3}\right]$-glc- \\
\hline 14 & Rebaudioside I & RI & $\mathrm{glc}^{3}-\mathrm{glc}-$ & $\mathrm{glc}^{2}-\left[\mathrm{glc}^{3}\right]-\mathrm{glc}-$ \\
\hline 15 & Rebaudioside J & $\mathrm{RJ}$ & rha $^{2}$-glc- & $\mathrm{glc}^{2}-\left[\mathrm{glc}^{3}\right]-\mathrm{glc}-$ \\
\hline 16 & Rebaudioside K & RK & $\mathrm{glc}^{2}-\mathrm{glc}-$ & $\mathrm{rha}^{2}-\left[\mathrm{glc}^{3}\right]-\mathrm{glc}-$ \\
\hline 17 & Rebaudioside L & RL & glc- & $\mathrm{glc}^{6}-\mathrm{glc}^{2}-\left[\mathrm{glc}^{3}\right]-\mathrm{glc}-$ \\
\hline 18 & Rebaudioside M & $\mathrm{RM}$ & $\mathrm{glc}^{2}-\left[\mathrm{glc}^{3}\right]-\mathrm{glc}-$ & $\mathrm{glc}^{2}-\left[\mathrm{glc}^{3}\right]-\mathrm{glc}-$ \\
\hline 19 & Rebaudioside N & $\mathrm{RN}$ & $\mathrm{rha}^{2}-\left[\mathrm{glc}^{3}\right]-\mathrm{glc}-$ & $\mathrm{glc}^{2}-\left[\mathrm{glc}^{3}\right]-\mathrm{glc}-$ \\
\hline 20 & Rebaudioside $\mathrm{O}$ & RO & $\mathrm{glc}^{3}-\mathrm{rha}^{2}-\left[\mathrm{glc}^{3}\right]-\mathrm{glc}-$ & $\mathrm{glc}^{2}-\left[\mathrm{glc}^{3}\right]-\mathrm{glc}-$ \\
\hline 21 & Dulcoside A & DA & glc- & rha $^{2}$-glc- \\
\hline 22 & Dulcoside B & DB & H- & rha $^{2}-\left[\mathrm{glc}^{3}\right]$-glc- \\
\hline
\end{tabular}




\section{Figure captions}

Figure 1. Backbone structures of steviol glycosides.

Figure 2. The 16S rDNA sequence of $M$. barkeri XJ.

Figure 3. Phylogenetic tree of M. barkeri XJ.

Figure 4. LC-MS and IR spectrum of product. (a) LC-MS of STE, (b) LC-MS of RS,

(c) IR spectrum of new product and STE standard.

Figure 5. Effects of inoculum concentration on conversion of STV.

Figure 6. Time courses of conversion efficiencies from steviol glycosides.

Figure 7. Typical HPLC chromatograms obtained at different times of steviol glycosides solutions treated with $M$. barkeri XJ (a, HPLC chromatogram of 1\% STE glycosides solution; b, HPLC chromatogram of conversion medium after $12 \mathrm{~h}$ treatment; c, HPLC chromatogram of conversion medium after $24 \mathrm{~h}$ treatment; d, HPLC chromatogram of conversion medium after complete conversion of steviol glycosides).

Figure 8. Deglycosylation pathways of steviol glycosides in M. barkeri. 


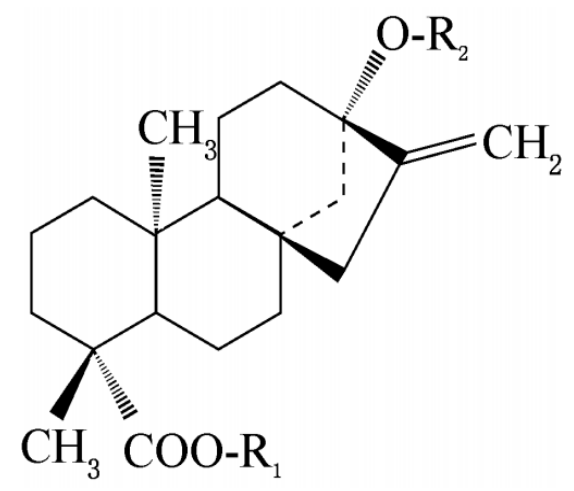

Figure 1. Backbone structures of steviol glycosides.

CAGAGTTTGA TCCTGGCTCA GGATGAACGC TGGCGGCGTG CTTAACACAT

51 GCAAGTCGAA CGATGAAGCC CAGCTTGCTG GGTGGATTAG TGGCGAACGG

101 GTGAGTAACA CGTGAGCAAC CTGCCCCTGA CTCTGGGATA ACAGCCGGAA

151 ACGGTTGCTA ATACCGGATA TGCATCATGG CCGCATGGTC TGTGGTGGGA

201 AAGATTTTTC GGTTGGGGAT GGGCTCGCGG CCTATCAGCT TGTTGGTGAG

251 GTAGTGGCTC ACCAAGGCGT CGACGGGTAG CCGGCCTGAG AGGGTGACCG

301 GCCACACTGG GACTGAGACA CGGCCCAGAC TCCTACGGGA GGCAGCAGTG

351 GGGAATATTG CACAATGGGC GGAAGCCTGA TGCAGCAACG CCGCGTGAGG

401 GATGACGGCC TTCGGGTTGT AAACCTCTTT TAGCAGGGAA GAAGCGTAAG

451 TGACGGTACC TGCAGAAAAA GCGCCGGCTA ACTACGTGCC AGCAGCCGCG

501 GTAATACGTA GGGCGCAAGC GTTATCCGGA ATTATTGGGC GTAAAGAGCT

551 CGTAGGCGGT TTGTCGCGTC TGCTGTGAAA ACCCGAGGCT CAACCTCGGG

601 CCTGCAGTGG GTACGGGCAG ACTAGAGTGC GGTAGGGGAG ATTGGAATTC

651 CTGGTGTAGC GGTGGAATGC GCAGATATCA GGAGGAACAC CGATGGCGAA

701 GGCAGATCTC TGGGCCGTTA CTGACGCTGA GGAGCGAAAG GGTGGGGAGC

751 AAACAGGCTT AGATACCCTG GTAGTCCACC CCGTAAACGT TGGGAACTAG

801 TTGTGGGGGC CTTTCCACGG TCTCCGTGAC GCAGCTAACG CATTAAGTTC

851 CCCGCCTGGG GAGTACGGCC GCAAGGCTAA AACTCAAAGG AATTGACGGG

901 GACCCGCACA AGCGGCGGAG CATGCGGATT AATTCGATGC AACGCGAAGA

951 ACCTTACCAA GGCTTGACAT ACACCGGAAA CGTCTGGAAA CAGTCGCCCC

1001 TTTTTGGTCG GTGTACAGGT GGTGCATGGT TGTCGTCAGC TCGTGTCGTG 1051 AGATGTTGGG TTAAGTCCCG CAACGAGCGC AACCCTCGTT CTATGTTGCC 1101 AGCACGTCAT GGTGGGAACT CATGGGATAC TGCCGGGGTC AACTCGGAGG 1151 AAGGTGGGGA TGACGTCAAA TCATCATGCC CCTTATGTCT TGGGCTTCAC 1201 GCATGCTACA ATGGCCGGTA CAAAGGGCTG CAATACCGTG AGGTGGAGCG 1251 AATCCCAAAA AGCCGGTCCC AGTTCGGATT GAGGTCTGCA ACTCGACCTC 1301 ATGAAGTCGG AGTCGCTAGT AATCGCAGAT CAGCAACGCT GCGGTGAATA 1351 CGTTCCCGGG TCTTGTACAC ACCGCCCGTC AAGTCATGAA AGTCGGTAAC 1401 ACCTGAAGCC GGTGGCCTAA CCCCTTGTGG GAGGGAGC

Figure 2. The 16S rDNA sequence of M. barkeri XJ. 


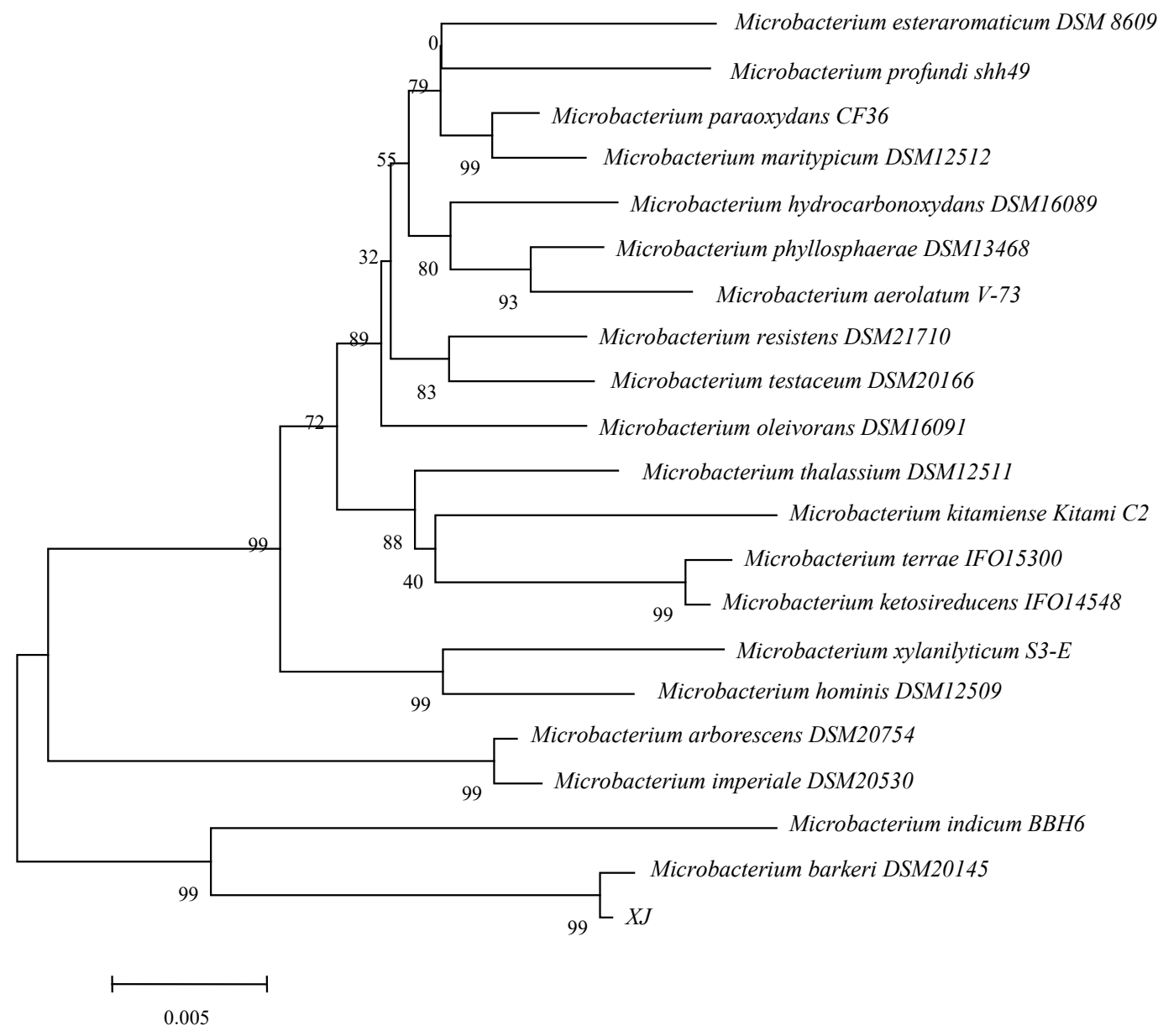

Figure 3. Phylogenetic tree of M. barkeri XJ. 

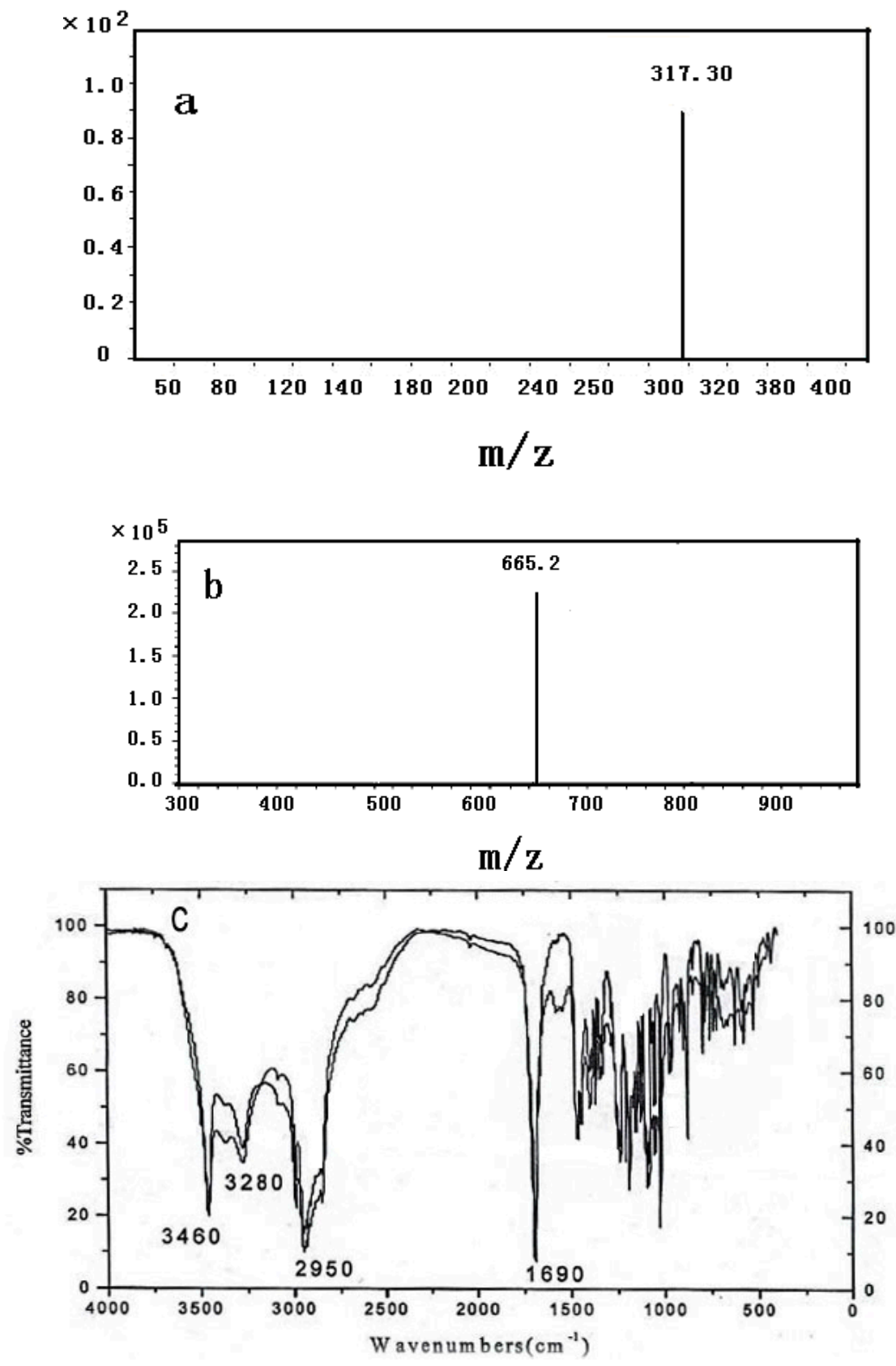

Figure 4. LC-MS and IR spectrum of product. (a) LC-MS of STE, (b) LC-MS of RS, (c) IR spectrum of new product and STE standard. 


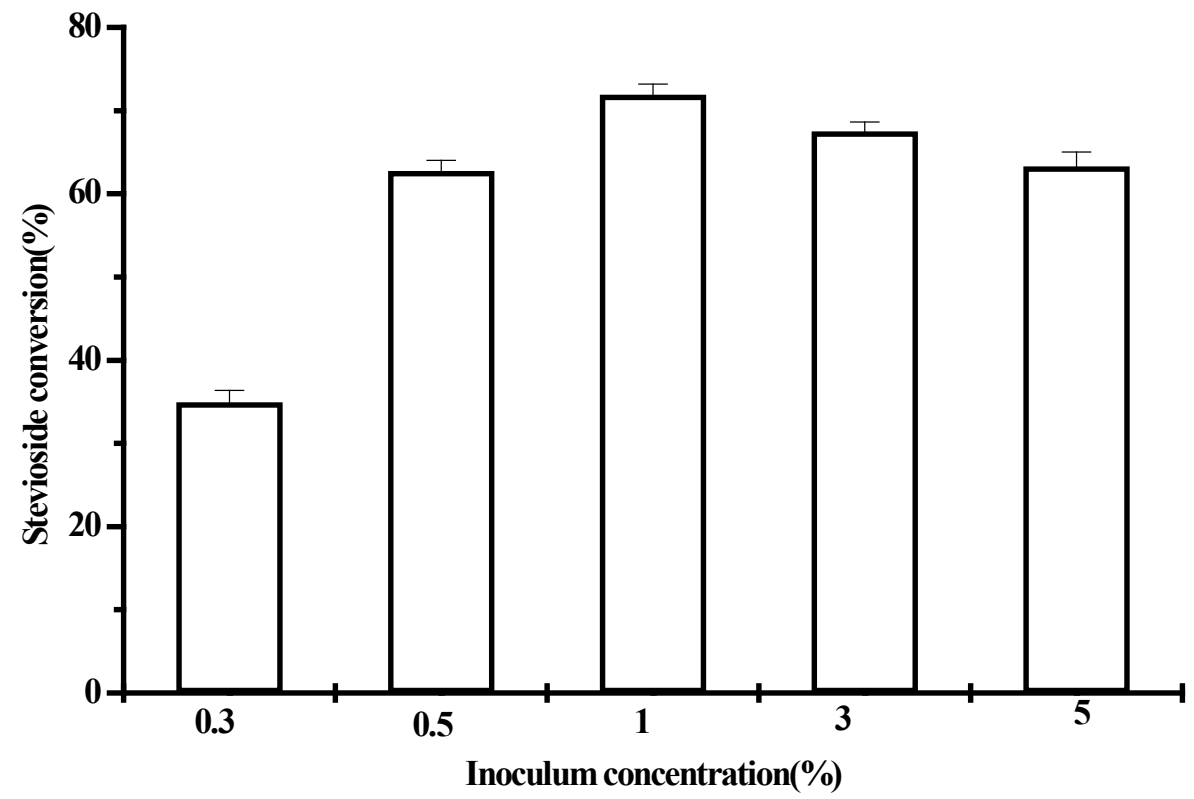

Figure 5. Effects of inoculum concentration on conversion of STV. 


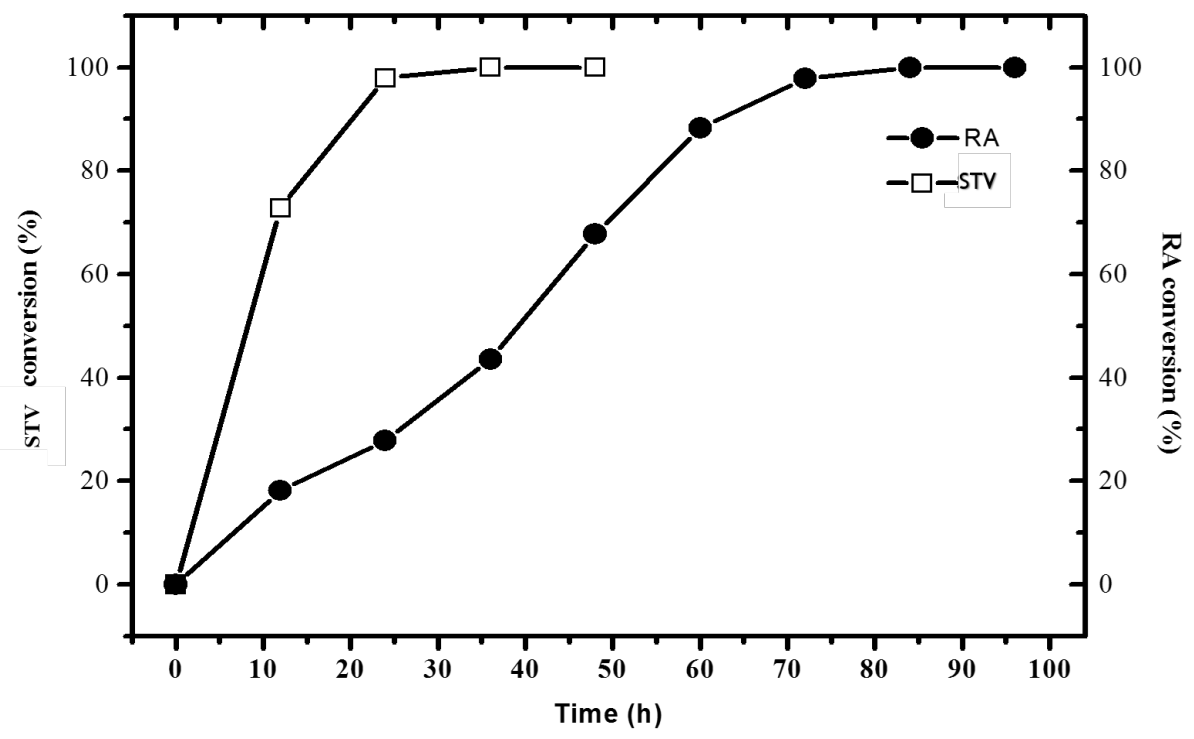

Figure 6. Time courses of conversion efficiencies from steviol glycosides. 

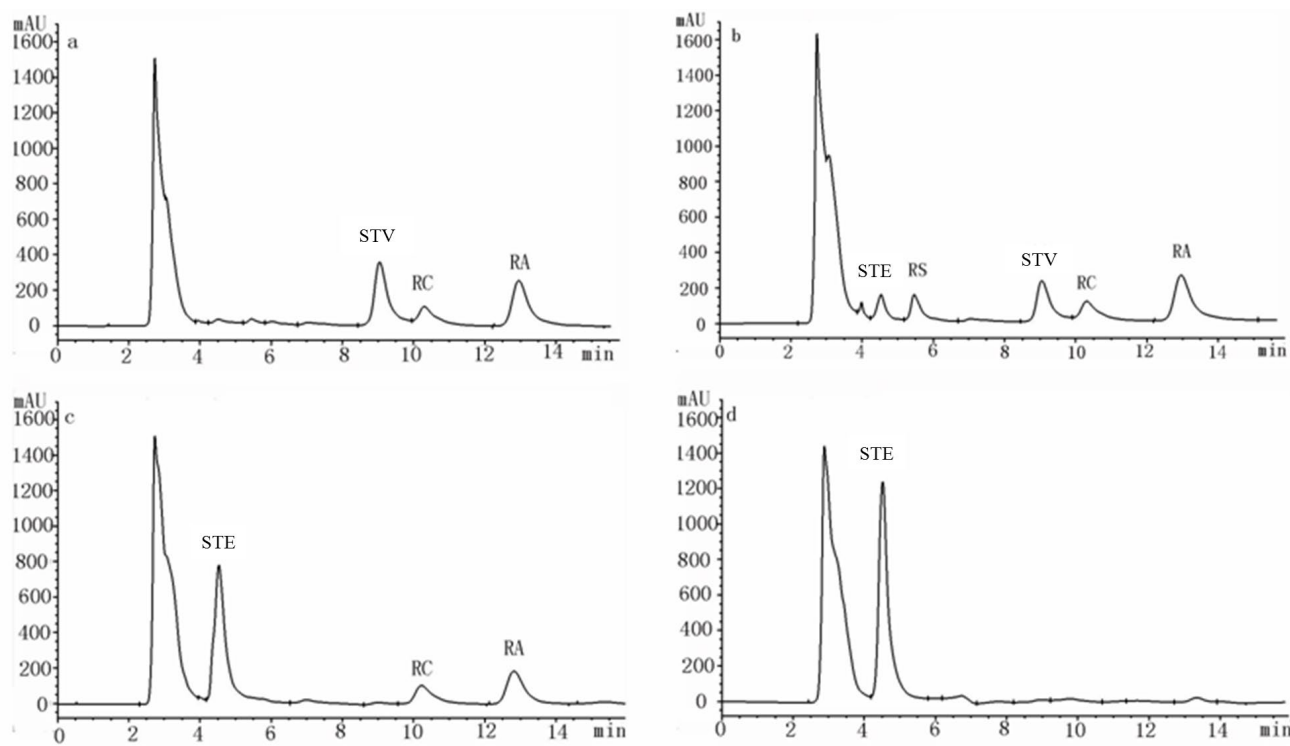

Figure 7. Typical HPLC chromatograms obtained at different times of steviol glycosides solutions treated with M. barkeri XJ (a, HPLC chromatogram of $1 \%$ steviol glycosides solution; b, HPLC chromatogram of conversion medium after $12 \mathrm{~h}$ treatment; c, HPLC chromatogram of conversion medium after $24 \mathrm{~h}$ treatment; $\mathrm{d}$, HPLC chromatogram of conversion medium after complete conversion of steviol glycosides). 

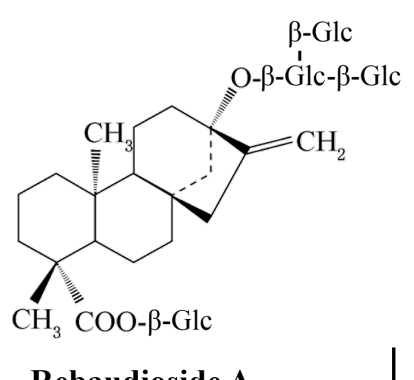

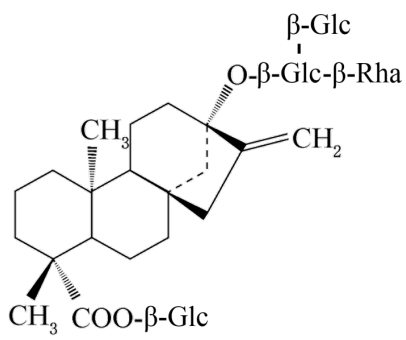

Rebaudioside C
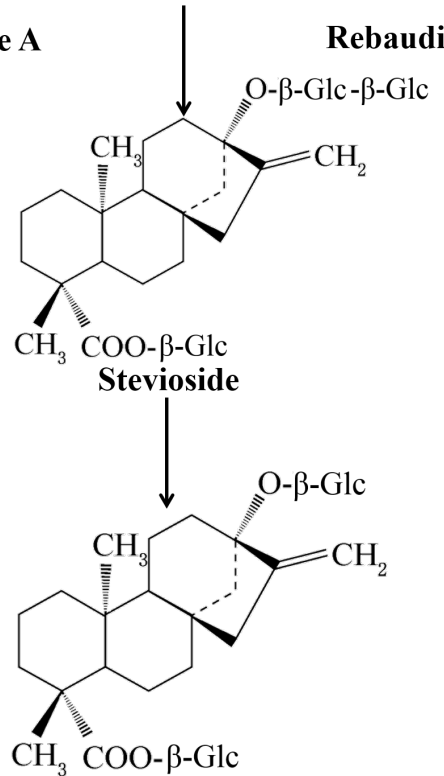

Rubusoside

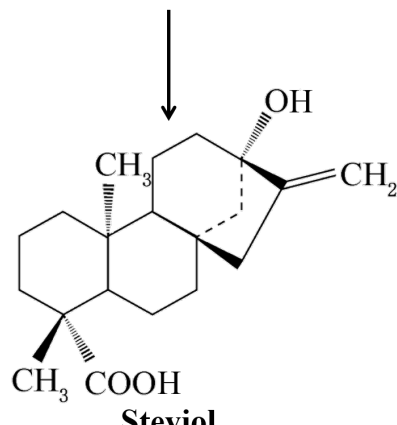

Steviol

Figure 8. Deglycosylation pathways of steviol glycosides in M. barkeri. 